\title{
Jacques-Pierre Gougeon - L'Allemagne du XXIe siècle, une nouvelle nation? - Éditions Armand Colin, collection « Éléments de réponse », 2009, 192 pages
}

\section{Thierry Pouch}

\section{(2) OpenEdition}

\section{Journals}

Édition électronique

URL : http://journals.openedition.org/economierurale/3325

DOI : 10.4000/economierurale.3325

ISSN : 2105-2581

Éditeur

Société Française d'Économie Rurale (SFER)

Édition imprimée

Date de publication : 21 octobre 2011

Pagination : 192-193

ISSN : 0013-0559

Référence électronique

Thierry Pouch, « Jacques-Pierre Gougeon - L'Allemagne du XXIe siècle, une nouvelle nation ? - Éditions Armand Colin, collection «Éléments de réponse », 2009, 192 pages », Économie rurale [En ligne],

325-326 | septembre-décembre 2011, mis en ligne le 17 octobre 2011, consulté le 24 septembre 2020. URL : http://journals.openedition.org/economierurale/3325 ; DOI : https://doi.org/10.4000/ economierurale.3325 
Jacques-Pierre GOUGEON

L'Allemagne du xxıe siècle, une nouvelle nation?

Éditions Armand Colin,

collection «Éléments de réponse », 2009, 192 pages

$V^{2}$ ilà un ouvrage qui est passé à peu près inaperçu lors de sa parution il y a un peu plus d'un an, notamment chez les économistes. Et l'on se demandera sans doute ce qui justifie que I'on en produise une note de lecture dans une revue comme Économie rurale. En quoi, en effet, une analyse portant sur l'évolution de la société allemande dans son ensemble, sur la politique intérieure et extérieure menée depuis l'effondrement du Mur de Berlin, sur la volonté de restaurer une puissance économique et diplomatique corsetée par les accords internationaux à la suite du choc de la Seconde Guerre mondiale et de ses atrocités, peut-elle faire l'objet d'un compterendu de lecture dans une revue dont le champ d'investigation est circonscrit aux seules dimensions de l'économie rurale et que, précisément, Jacques-Pierre Gougeon ne mentionne à aucun moment dans son ouvrage l'agriculture et le rural ?

Pourtant, la lecture à laquelle invite cette note, s'impose. On sait en effet qu'une abondante littérature et de nombreux commentaires se sont répandus ces derniers mois pour aborder le problème du différentiel de compétitivité entre les agricultures de I'Union européenne (UE), et plus spécifiquement entre celles de la France et de I'Allemagne. Le constat selon lequel I'agriculture française - l'industrie de la transformation n'échappant pas au processus perdait des parts de marché a alerté tous les acteurs de la branche agricole, à commencer par les producteurs euxmêmes. En a découlé une multitude de débats centrés à la fois sur les distorsions de concurrence qu'occasionneraient des charges salariales divergentes entre les deux principaux pays producteurs agricoles de l'UE, et sur l'usage et l'application de règlements européens.

Surplombant la thématique des charges des exploitations agricoles, c'est tout le problème de la spécialisation des pays membres qui refaisait surface à cette occasion. La construction européenne avait en effet opéré un découpage des systèmes productifs et donc des spécialisations internationales des pays membres. Concernant I'Allemagne et la France, ce découpage correspondait en quelque sorte à des héritages historiques, la puissance industrielle allemande s'étant constituée tout au long de la seconde moitié du XIXe siècle, alors que les atouts dont disposait la France en matière agricole la prédisposaient à prendre le leadership européen en ce domaine.

L'effondrement du Mur de Berlin a rebattu les cartes et redessiné la géographie de l'économie et de l'agriculture européennes. C'est là que la lecture de l'ouvrage de Jacques-Pierre Gougeon se révèle d'un grand secours.

Composé de trois parties abordant successivement la puissance allemande du xxIe siècle, le paysage politique interne et le " modèle économique et social en mutation ", l'ouvrage offre au lecteur qui s'est penché sur la problématique du différentiel de compétitivité agricole entre I'Allemagne et la France une opportunité d'en saisir les tenants et les aboutissants.

La première partie du livre apparaît de ce point de vue des plus éclairantes. La recherche de la puissance économique et diplomatique, destinée à peser sur les affaires du monde, distingue une Allemagne désormais désinhibée de son 
passé. Cette évolution résulte d'une évolution intellectuelle et idéologique propre à une génération - la Chancelière Angela Merkel en est issue - qui, en dépit de I'histoire, n'entend plus faire de son pays une nation perpétuellement traumatisée par le nazisme. Libérée de son passé et de la partition du pays, ayant digéré le choc de la réunification, l'Allemagne s'est rapidement projetée comme une nation puissante, la plus puissante de I'Union européenne, devant assumer sa part de responsabilité et de pouvoir dans l'économie mondiale et au sein des Nations-Unies. On assiste bel et bien selon I'auteur à la fin de cette Europe communautaire construite en partie pour contrôler le voisin allemand.

Et l'agriculture dans tout cela ? Au regard de ces "éléments de réponse »nom de la collection -, l'économiste agricole pourra les mobiliser et faire fructifier son imagination afin d'interpréter la montée en puissance du complexe agroalimentaire allemand sur les marchés européens et tiers, que ce soit dans le secteur de la viande porcine, du lait et des produits laitiers ou encore, mais plus modestement, des céréales. II n'y avait pas de raisons objectives d'écarter l'agriculture de cette volonté de puissance, et les Allemands ont sans doute à la fois anticipé l'évolution de la demande mondiale de produits agricoles et alimentaires, et les décisions qui se préparent en matière de réforme de la politique agricole commune.
Reste que, et c'est l'une des principales limites de l'ouvrage de JacquesPierre Gougeon, I'analyse qui est livrée ne se penche nullement sur les conséquences d'une telle stratégie sur la poursuite de la construction européenne. La stratégie allemande est d'un certain point de vue porteuse de tensions, de conflits, de mésententes entre les pays membres et avec la France plus particulièrement. Elle participe de l'affirmation progressive des forces centrifuges, lesquelles, si elles l'emportent sur les forces centripètes de la formation d'une Europe unie, présage d'une arrivée aux limites de cet objectif, ainsi qu'en témoigne la crise des dettes souveraines au sein de la zone euro. S'agissant de l'agriculture, on peut légitimement s'interroger sur la durabilité de la position franco-allemande affichée en septembre 2010. L'évolution de la PAC et les appétits de puissance de l'Allemagne dans une économie mondiale se distinguant par un déplacement de son centre de gravité laissent entendre qu'il ne s'agirait que d'un accord de façade.

En tous les cas un livre à lire pour les éléments de compréhension qu'il fournit sur la mutation de l'Allemagne et de son économie.

Thierry POUCH

APCA, Pôle économie et politiques agricoles

Laboratoire organisations marchandes et institutions, Université de Reims Champagne-Ardenne 